\title{
Blame the Message Senders Not the Messenger: The Defence Case of the English "Native Speaker" Teacher
}

\author{
Muneer Hezam Alqahtani iD \\ College of Education, King Faisal University Saudi Arabia, Hofuf 36363, Saudi Arabia \\ Correspondence should be addressed to Muneer Hezam Alqahtani; mhalqahtani@kfu.edu.sa
}

Received 3 November 2021; Revised 15 December 2021; Accepted 18 December 2021; Published 13 January 2022

Academic Editor: Ehsan Namaziandost

Copyright ( 2022 Muneer Hezam Alqahtani. This is an open access article distributed under the Creative Commons Attribution License, which permits unrestricted use, distribution, and reproduction in any medium, provided the original work is properly cited.

\begin{abstract}
This article investigates how "native speaker" teachers define who a "native speaker" is and how they view themselves in relation to the concept. It further explores how they feel about discriminatory practices in employability and the pay gap that are systemically carried out against their "nonnative speaker" counterparts by recruiters. Data were gathered from 10 English language teachers: five males and five females from the UK, Canada, Ireland, and South Africa, who were hired by a state university in Saudi Arabia on the basis that they are "native speakers." The findings show that although the place of birth and the official status of English in a given country were the main defining criteria for hiring a "native speaker," the interviewees did not view the concept of the "native speaker" in the same ways as their recruiters did, who they believed used those criteria in an overly simplistic and reductive way rooted in native-speakerism. The findings also show that the participants did not enjoy the unjustified privileges given to them by their recruiters at the expense of their "non-native speaker" colleagues. Instead, in some cases, they attempted to confront their recruiters over such discriminatory practices, and in some others, they attempted to bridge the gap and ease the tension between themselves and their "nonnative speaker" counterparts, although these efforts were hindered by the system's unfair and unjust practices.
\end{abstract}

\section{Introduction}

The "native vs. nonnative" dichotomy has featured in TESOL scholarly debates for decades and has been widely discussed from a number of different perspectives such as that of students (e.g., [1-5]) and of recruiters (e.g., [5-10]). It is alleged that individuals who come from countries such as the USA, the UK, Australia, New Zealand, South Africa, or Canada predominantly are considered to be "native speakers" of English, whilst English speakers who live elsewhere are "nonnative speakers" [11]. Following Holliday [12], this article also places the terms "native speaker(s)" and "nonnative speaker(s)" inside inverted commas, not because it argues that there are two clearly defined and separate groups of English speakers: "natives" and "nonnatives," but because that is how they are termed in the discourse. Even though a large number of studies have problematised these divisions (e.g., [12-23]), the division between "native speakers" and "nonnative speakers" continues to persist in the TESOL domain, causing serious damage to those who are identified as "nonnative speakers." Holliday [24] argues that one form of this damage is the discrimination against "nonnative speakers" when it comes to employment opportunities and remuneration at English language schools (see also [12-23,25]). Many English language schools consider being a "native speaker" a requirement when recruiting English language teachers $[8,9,26]$ despite the lack of linguistic evidence to support the validity of such a distinction $[12,18]$. For that reason, Holliday [12] asserts that this distinction has no linguistic grounds but rather is ideologically and politically motivated. He terms this distinction "native-speakerism" whereby there is "an unequal power relationship between different regions of the world-between a well-resourced, politically and economically aggressive, colonising, Western "Centre" and an under-resourced, colonised Periphery" (p. 2). According to 
Holliday, there is "an established belief that "native speaker" teachers represent a "Western culture" from which spring the ideals both of the English language and of English language teaching methodology" (p. 6). As a result, "nonnative" speaker teachers are seen as "dependent, hierarchical, collectivist, reticent, indirect, passive, docile, lacking in self-esteem, reluctant to challenge authority, easily dominated, undemocratic, traditional, Confucian, Islamic ... etc." ([12], p. 19). Consequently, even when they are considered for a teaching position, some "nonnative" applicants are stigmatised and required to provide advanced academic qualifications and years of teaching experience beyond those required of their "native speaker" counterparts [27]. After recruitment, they are also paid less than their native speaker counterparts [28-30].

Since "native speaker" teachers are prioritised and favoured by many recruiters [6,31-34], and therefore are seen to have major advantages over their "nonnative speaker" counterparts, this article investigates two issues. The first investigates how "native speakers" themselves define the term and who they consider to be a "native speaker." The second issue focuses on their views regarding injustices against their "nonnative speaker" teachers in areas such as the pay gap between them and the unequal opportunities provided to each group.

This article draws its data from 10 English language teachers from the UK, Canada, and South Africa who were recruited by a Saudi state university on the assumption that they were "native speaker" teachers. In-depth and focus group interviews were conducted to explore the perspectives of the "native speakers" themselves. The findings show that although the place of birth and the official status of English in a given country are the two main defining factors for a "native speaker," the participants" provided more complex definitions which were far from the simplistically straightforward definitions imposed on them by recruiters and students. The findings further show that they greatly disapprove of discriminatory practices against their "nonnative speaker" colleagues when it comes to employment opportunities or pay. In addition, the fact that "native speaker" teachers are advantaged induced negative feelings of guilt and stress.

\section{Research Problem}

Although many English language schools consider the "native speaker" status as a requirement for hiring English language teachers (e.g., $[8,9,26]$ ), little is known about how those recruited on that basis themselves see this concept and how they feel about the undue privileges this term confers upon them financially, how it disadvantages their nonnative speaker colleagues in a number of ways, and how it can affect the working relations between the two groups.

Given that no consensus has yet been reached, the term "native speaker" continues to be both contentious and contested. Whilst some studies have linked the definition of a "native speaker" to the individual's ethnicity [18,21,24,35] in which "whiteness" is the norm $[13,18,27,36]$, others (e.g., $[6,31-34])$ have pointed to the role that place of birth plays in identifying who is considered to be a "native speaker." Other scholars however (e.g., $[6,13,37,38]$ ) have highlighted that accent is a defining factor in determining who is a "native speaker," whilst nationality was the main defining factor of a "native speaker" in some other studies (e.g., [6,7,39]). However, the range of factors employed to define who is a "native speaker" and who is not shows clearly that there is no agreed upon definition for the term. Rather, the term "native speakers" seems to be oversimplified and loosely defined, depending on those who define it. This article seeks to offer further insights into the scholarly discussion on this topic by providing evidence from "native speakers" themselves, a perspective which has not been investigated sufficiently. Although loosely defined as "native speakers" by recruiters and students, in effect "native speakers" are the last group to have a say in defining themselves. This article seeks to fill that gap in the literature by giving voice to the perspectives of "native speaker" teachers themselves.

\section{Literature Review}

3.1. Native-Speakerism. Paikeday [40] problematised the notion of native-speakerism more than three decades ago when he asserted that the "native speaker" "exists only as a figment of a linguist's imagination" (p. 12). Later, Phillipson [41] argued that the concept is a fallacy and has no objective reality but is rather a social construct $[42,43]$. In response, Rampton [44] proposed the alternative term "expert speaker" to denote every fluent speaker of English. In this case, the status of being a "native speaker" is not acquired solely by birth; rather, any speaker who masters English at a later stage of life can still be considered a "native speaker" $[34,45]$. As Jenkins [46] points out, in multilingual countries such as India, English is spoken at home alongside other local languages, which blurs any distinction between one's first and second language. Moreover, Kramsch [47] claims that "native speakers" do not speak a more idealised or standardised form of English than "nonnative speakers." In reality, their variety of English-just like that of "nonnative speakers"-is influenced by different factors such as age, geography, and social status. Therefore, drawing any clear distinction between "native speakers" and "nonnative speakers" remains both problematic and illusory.

Despite the fact that a number of studies have problematised the "native speaker" notion (e.g., [12-23]), the idea still holds sway in the TESOL field. However, as Holliday [12] points out, the relationship between the "native speaker" concept and native-speakerism has still not been fully acknowledged.

Although the native-nonnative speaker division is wellestablished as a problem, as an ideology, native-speakerism has almost disappeared between the lines of our everyday professional lives. This is particularly damaging because issues may appear to have been solved when in fact they have not (p. 11).

Indeed, Holliday [18] goes further to argue that nativespeakerism ideology is a form of neo-racism which creates a culturally deficient "Other" on the one hand whilst simultaneously linking the "native speaker" to "whiteness" on the other hand. 
Furthermore, from an intercultural perspective, Byram [48] critiques the "native speaker" model in two ways. First, as requiring learners to copy and imitate the "native speaker" is an impossible task, he asserts that pursuing it will lead to an inevitable failure because such a requirement "ignores the conditions under which learners and native speakers learn and acquire a language" (p. 44). There is considerable literature which shows that even bilinguals who have acquired both languages from birth have different levels of linguistic competence and that competence in one language will always exceed competence in the other. The second critique of modelling the "native speaker" that Byram [48] puts forward is that even if learners did manage to master two languages with the same competence, doing so would create an undesirable form of competence in that it would imply that a learner should be linguistically schizophrenic, abandoning one language in order to blend into a second linguistic environment, becoming accepted as a native speaker by other native speakers, and then going back to the first. This linguistic schizophrenia also suggests abandoning one social group and its culture and the acquisition of a native sociocultural competence and a new social identity, as a result of "passing" into another group. The strains involved in this process, even if it were desirable and possible, are related to the psychological stress of "culture shock"... and [are] permanently damaging ([48], p. 44).

As the discussion above suggests, the social construct of native-speakerism is damaging not only to "nonnative speaker" teachers but also to "native speaker" teachers and students because it shifts the focus away from creating an "intercultural speaker" who is capable of achieving successful communication in different scenarios and situations.

\subsection{The Privilege of the "Native Speaker" Teacher in Saudi} Arabia. Since the context of this study is a state university in Saudi Arabia, it is essential to review a number of studies that have addressed the "native vs. nonnative" dichotomy in that country. Alseweed [49] studied the perceptions of 169 university students towards their "native speaker" and "nonnative speaker" teachers in the classroom. This study revealed that when the students reached an advanced linguistic level, they preferred their "native speaker" teachers over their "nonnative speaker" counterparts. However, they showed some preference for their "nonnative speaker" teachers when it came to understanding their needs because these teachers were more responsive to and empathetic towards their students. Similarly, Qadeer [50] investigated the perceptions of 136 university students towards their "native speaker" and "nonnative speaker" teachers. The findings revealed that the students preferred "native speaker" teachers when it comes to teaching speaking and listening. On the contrary, the "nonnative speaker" teachers were preferred when it comes to teaching reading and grammar. Although at first glance the students' preference for "nonnative speaker" teachers' teaching of grammar and reading may seem helpful in settling the "native vs. nonnative" dichotomy, this preference did not extend to the conversational skills of listening and speaking because such skills are owned by the "native speaker" $[12,51,52]$. When it comes to investigating the recruiters' perspectives, Alenazi [7] surveyed 56 TESOL recruiters in Saudi Arabia and concluded that nationality, accent, academic qualifications, years of experience, and being a "native speaker" were the main criteria for hiring English language teachers.

All of the previous studies used the terms "native speaker" teachers without providing a solid identification for who counts as a "native speaker." For this reason, more recently, Alqahtani [6] investigated the "native vs. nonnative" dichotomy from the recruiters' perspectives and concluded that the place of birth (e.g., the USA, the UK, Canada, Australia) and the accent of the speaker (e.g., Received Pronunciation or General American English) were the main criteria English schools' recruiters used to define "native speakers." Furthermore, the recruiters believed that "native speaker" teachers should receive higher payment than their "nonnative speaker" counterparts, even though the recruiters were not "native speakers" themselves.

3.3. Pay Gap between "Native Speaker" and "Nonnative Speaker" Teachers. Although it is well-established that "nonnative speaker" teachers receive unequal job opportunities and are paid less compared to their "native speaker" counterparts, it is hard to quantify the difference in their remuneration since pay is a sensitive topic for most individuals [53]. Nevertheless, a few studies have attempted to investigate the differences in how "native speaker" and "nonnative speaker" teachers are remunerated and the benefits each group receives. For instance, in South Korea, "native speaker" teachers are offered free air fares, free accommodation, and paid healthcare insurance in addition to a salary which is also higher than that of their "nonnative" counterparts [29]. In Thailand, the gap between "native" and "nonnative" teachers was found to be even greater. Saengngoen [30] points out that less qualified "native speaker" teachers are paid twice as much as "nonnative speaker" teachers who hold a $\mathrm{PhD}$. Indonesia provides another example of where a significant pay gap occurs. Griffith [28] asserts that, in addition to free accommodation, "native speaker" teachers are paid 10 times more than their "nonnative" counterparts. These examples demonstrate that, in addition to the unequal opportunities and challenges that "nonnative speaker" teachers face in securing a teaching position, even when they are recruited, they are paid significantly less.

The studies noted above provide examples of the inequality in the TESOL profession that recruiters and/or students have been imposing on "nonnative speaker" teachers for decades. Despite the existence of a large body of literature that has problematised such inequity and its implications, this paper contributes further to the existing literature in three different ways. First, this article investigates how "native speaker" teachers view themselves in relation to the term. In doing so, it gives them an opportunity to explore the narrowness with which many recruiters, students, and scholars use the term "native speakers." Second, as Ruecker [27] notes, just as their 
"nonnative speaker" counterparts are doomed to have unfair disadvantages because of the place where they were born or the accent they speak with, "native speaker" teachers are also doomed to enjoy unjustified privilege and advantages. Third, this article gives voice to the "native speaker" teachers by offering them an opportunity to express how they truly feel about this privilege.

\subsection{Native-Speakerism and Intercultural Communication} Competence. It is not possible to discuss native-speakerism and modelling the "native speaker" without mentioning the importance of intercultural communication competence in language teaching and learning. Byram's $[48,54]$ five savoirs (attitudes-savoir être; knowledge-savoir; skills of interpreting and relating-savoir comprendre; skills of discovery and interaction-savoir apprendre/faire; and critical cultural awareness-savoir s'engager) offer a comprehensive view of what language teachers should equip their students with and so expand language teaching and learning beyond the purported linguistic skills which favour the model of the "native" over the "nonnative" speaker teacher in recruitment practices. With this in mind, recruiters should move away from simplistic hiring criteria based on an individual's place of birth, accent when speaking English, etc., towards hiring teachers with the requisite skills to help language learners to become intercultural speakers.

\section{Methodology}

4.1. Design. This study uses phenomenological interviews because phenomenology focuses on the lived experiences of individuals and how they perceive and shape realities $[55,56]$. For that reason, phenomenology offers an appropriate methodological framework through which to investigate how "native speaker" teachers view themselves in relation to the term and to explore their views on discriminatory practices around employability and the pay gap between them and their "nonnative speaker" colleagues. It is not possible to properly explore these issues without viewing them from the perspectives of the individuals who are living (i.e., "native speaker" teachers).

4.2. Participants. Five female and five male English language teachers at a state university in Saudi Arabia participated in this study. They come from diverse national and cultural backgrounds. However, they all were recruited by a state university in Saudi Arabia on the assumption that they are "native speakers." The names given to the participants are pseudonyms and do not relate either directly or indirectly to their real identities (Table 1).

4.3. Instruments. As Burgess [57] points out, conversations are an effective way to access reality. Therefore, in order to access the reality of how "native speaker" teachers view themselves in relation to the term and to explore their views on discriminatory practices around employability and the pay gap between them and their "nonnative speaker" colleagues, focus group interviews were used in this study because they are designed to "elicit perceptions, information, attitudes and ideas from a group in which each participant possesses experience with the phenomenon under study. The interviewees are often members of a program, class, department, college, or university" ([58], p. 50). Therefore, focus interviews were deemed to be an appropriate method for data collection since all of the participating teachers work at the same university and had been recruited on the basis of their "native speaker" status.

4.4. Procedure. The interviews were conducted using Zoom Meetings software for two reasons. First, the COVID-19 protective measures in Saudi Arabia, which prohibit social gatherings, were in place at the time of conducting the interviews. Therefore, it was not possible to conduct the interviews in person. Second, although some of the participants were on holiday in their home countries, they were keen to take part in the study virtually. Video conferencing programs are becoming more popular in qualitative research because they "provide researchers with a cost-effective and convenient alternative to in-person interviews" ([59], p. 1292). The implementation of COVID-19 restrictions in many countries has seen an increasing shift away from inperson qualitative research interviews to virtual platforms ([60], p. 1). Therefore, Zoom Meetings offered an efficient virtual platform that enabled the interviews to be conducted effectively.

4.5. Data Analysis. Thematic content analysis [61] was used to analyse the data in this study. Researchers have to immerse themselves in the data before starting their initial coding, which creates larger themes [62]. Therefore, guided by the research questions and the objectives of the study, data related to the interviewees' definitions of who a "native speaker" is and comments that discussed the pay gap were coded to create two larger themes (definition of "native speakers" and pay gap) which are the main focus of the study.

4.6. Research Questions. The study posed the following research questions:

(1) How do "native speaker" teachers view the concept of the "native speaker"?

(2) How do they feel about the discriminatory practices against "nonnative speaker" teachers that are systemically taking place in the TESOL profession?

\section{Findings}

The findings revealed two definitions of "native speakers." The first is the definition that is imposed on the participants by others such as recruiters and students, whilst the second indicates how the participants position themselves as "native" or "nonnative" speakers of English. When defined by others, the definition of a "native speaker" is usually based on the participant's place of birth, nationality, or accent. 
TABLE 1: Research participants profile.

\begin{tabular}{lcr}
\hline Name & Country & Years of English language teaching experience \\
\hline Kelly (female) & Canada & 10 years of teaching experience in Korea, Georgia, and Malaysia \\
Elena (female) & South Africa & 15 years of teaching experience in Korea and Saudi Arabia \\
Sally (female) & South Africa & 7 years of teaching experience in Bahrain and Saudi Arabia \\
Gina (female) & South Africa & 10 years of teaching experience in South Africa and Saudi Arabia \\
Sara (female) & South Africa & 5 years of English language teaching experience in Saudi Arabia \\
Paul (male) & United Kingdom & 20 years of teaching experience \\
Matt (male) & United Kingdom (Scotland) & 8 years of teaching experience \\
Bernie (male) & Republic of Ireland & 6 years of teaching experience in Thailand, \\
Adam (male) & United Kingdom & Vietnam, the UK, and Saudi Arabia \\
Mohammed (male) & United Kingdom & 14 years of teaching experience in Saudi Arabia \\
\hline
\end{tabular}

When asked to define the term, the participants provided definitions that were more complicated and less straightforward than those used by their recruiters, in spite of the fact that they had all been recruited on the premise that they were "native speaker" teachers. The findings also show that the participants experience negative feelings such as guilt about and disapproval of the discriminatory practices against their "nonnative speaker" colleagues, even though these practices advantage them because of their perceived superior status as "native speaker" teachers.

\section{Discussion}

Defining a speaker as a "native speaker" is a common practice in TESOL. Although the Saudi university recruited the study participants on the basis of their nationality or place of birth, the participants themselves based their definition of being a "native speaker" not simply on one's place of birth or nationality but on two other main factors: speaking the language from early childhood and coming from a country where English was the/an official language.

6.1. Place of Birth. Some participants did judge an individual's place of birth to be a defining factor for a "native speaker." For example, Paul said the following:

I guess if you think about what's a native speaker, I would say a native speaker is someone who's brought up with the language. It's something that you're born into, so you're not conscious of learning the language. It's something .... Also, it's the first language that you come in contact with, so it's something you develop as a child. I think that's very important to being a native speaker, that defines a native speaker.

Gina too remarked on place of birth as an identifier of who counts as a "native speaker":

I would say, to add to that, being a native speaker is based on a socio-bio-developmental phase, that you were born speaking, with a family who speaks this language. You were socialised in this language ... what defines a native speaker is where you were born, and were you using this language. Were you socialised in this language? Do you dream in this language? You cry and laugh in this language?

Reducing the definition of a "native speaker" to one's place of birth is a common phenomenon in TESOL.
Individuals who live in countries such as the USA, the UK, Canada, Australia, or New Zealand are considered to be "native speakers" and therefore are prioritised when applying for English teaching jobs [32,33]. For example, when studying the preference for hiring "native speaker" teachers in the Gulf Cooperation Council (GCC) countries, Ali [31] found that the first requirement in a job advert in Saudi Arabia was to have been born in the UK, the USA, Canada, or Australia.

Nevertheless, some participants problematised such oversimplification when defining a "native speaker." For instance, Mohammed showed his frustration about the reduction of the definition of a "native speaker" to the place of birth, accent, or nationality:

I think someone should do a study on how to change the attitudes of the people who think that a native speaker should be someone from a particular country or nationality, or they should sound a specific way. I think maybe once that is done people start learning exactly what a native speaker is. It has nothing to do with where a person comes from.

Although Davies [34] is an advocate of defining a "native speaker" based on their place of birth, he realizes the oversimplification inherent in such a criterion and points out the following:

The native speaker is for a start one who can lay claim to being a speaker of a language by virtue of place or country of birth. But birth place alone as a defining characteristic seems too restricting since children can be moved very quickly after birth from one country to another. We need to add the notion of adoption as an alternative; the definition then becomes: by place or country of adoption (p. viii).

However, adding the concept of "place of adoption" as a defining factor of a "native speaker" still does not show the full extent of the matter's complexity. For example, if someone from the UK or the USA was born in a non-English-speaking country during his or her parents' sojourn abroad, they would not be considered a "native speaker," according to the criteria of place of birth and country of adoption [6]. Interestingly, Davies [34] elaborates on the complexity of the matter by asking whether a child born to non-English-speaking parents in the UK would be considered a "native speaker." These scenarios show the inherent problems of reducing the definition of a "native speaker" to the person's place of birth. Davies himself reached the conclusion that it is possible to "develop a full grammatical 
system in the second language and in that sense to become indistinguishable from those who have had only English input since birth" (2003, p. 67). One participant, Kelly, arrived at this same conclusion when she said the following:

I guess one could say it's probably someone who's been raised with a mother tongue language that is learned from birth. But again, language acquisition can happen in so many different ways, primarily through education, through immigration, living abroad even.

Similarly, Sally questions the place of birth as a defining factor for a "native speaker" and argues that language could be acquired at a later stage:

I haveve always believed that a native speaker could be anyone who has learned a certain language from an early age. It could be that someone speaks Arabic, and they learned English at an early age. I think that person would qualify to be called a native speaker of English or, again, what would be the difference if a person only learns English when they are in high school? But at the time, they are about 30-something years old, 35 years old, they are fluent enough in English. Would it also qualify them to be native speakers?

The discussion above shows that calling someone a "native speaker" based on their place of birth underestimates the complexity of the matter, especially since Kramsch [51] points out that being considered as a "native speaker" is more than a privilege of birth or even of education. It is acceptance by the group that created the distinction between native and nonnative speakers. The example of Elena throws further light on the idea of being accepted by the group that created this distinction. She was recruited by a Saudi state university on the basis that as a South African, she was a "native speaker"; yet, she does not really see herself as a "native speaker" in quite the same way that others might:

It depends on who is defining native speaker. If it maybe a potential employer that wants to have a certain group of individuals in his employ, they will define it differently. They would maybe add, "Having been born in $X, Y$, and $Z$ countries," as opposed to maybe somebody else would defines it differently. For example, in terms of my upbringing, I would not qualify as a native speaker for most intents and purposes. However, I did speak English from a very young age because my dad was English, but my mom and dad were divorced, so I spoke less English than what another person would speak. But I still consider myself fairly good at English.

Although Elena was born and raised in South Africa, she still does not view herself as a "native speaker" since as a child she spoke less English than Afrikaans. The basis on which she was recruited contradicts the fact that she views herself as a "nonnative speaker" and shows how reductive concepts such as place of birth are not necessarily factual realities but are imposed by others such as recruiters, who, in turn, are ideologically and politically motivated [18]. Therefore, unlike recruiters and students who use an individual's place of birth as a straightforward criterion for defining a "native speaker," this study's participants' conception of what constitutes a "native speaker" was rather different. Although all the participants were deemed by others to be "native speakers" by virtue of their place of birth alone, some problematised such a reductive definition. Indeed, some did not even consider themselves to be "native speakers," despite being considered so by those who had hired them on that basis. Furthermore, such reductive definitions also hinder the goal of encouraging learners to be "intercultural speakers" rather than imitating a "native speaker" model, which, as discussed previously, not only is unrealistic but also creates a power distance between the teacher and the learner [48].

Furthermore, the inability of "native speaker" teachers to pin down a clear and unambiguous definition of what constitutes a "native speaker" adds further evidence of the short-sightedness of using that criterion when recruiting TESOL teachers.

6.2. Official Language. Kachru's [63] three circles place South Africa within the category of the outer circle where English is used officially alongside other languages. There are 11 official languages in South Africa, one of which is English. The status of English as an official language of South Africa seems to have motivated the recruiters at the Saudi university to hire English teachers from South Africa on the assumption that the official status of English in South Africa grants their recruits the status of a "native speaker." Nonetheless, the South African participants showed mixed views on the subject. For example, Elena points out the following:

In terms of the definition of a native speaker, the generally accepted definition of a native speaker... I'm not. Am I bilingual? Yes, I'm fully bilingual. I speak two languages [English and Afrikaans] fluently. I do not mind communicating in either one of the two. My situational proficiency may be a little bit better in English.

Sara raised a similar point about bilingualism:

I would consider myself bilingual because we have 11 official languages, but I grew up with one parent who spoke English and another who spoke Afrikaans, but I do identify with English more because I went to English-speaking schools. Our first language would be English, and second would be Afrikaans. I consider myself bilingual.

Although Elena is more fluent in English than in Afrikaans, she still does not define herself as a "native speaker" of English. Instead, like Sara, she considers herself to be bilingual. These participants' desire to call themselves "bilinguals" rather than "native speakers" stems from the fact that they speak English with an Afrikaans accent, thus reflecting the idea any non-English accent in a speaker's speech disqualifies him or her from being a "native speaker" [64-66]. In this case, monolingualism is the norm when defining a "native speaker" [46].

Bernie too viewed the official use of a language in a given country to be a defining characteristic for "native speakers" from that particular country. He points out the following:

In Ireland, in my country, we have the two official languages, it is Irish, and there is English, but we all speak English natively and we learn Irish as a secondary language. 
For Ireland, I think Irish is still the native language, but also English is as well.

Although Irish is taught as a second language after English in Ireland, Bernie views it as a native language for Irish people because of the strong link between the Irish language and Irish identity. Here, he wants to emphasise the status of Irish as an official language, despite its decline [67] and the multiple attempts to revive its use more widely [68]. Watson [69] points out that "the Irish language has been a symbol of Irish national identity since the nineteenth century (and before) and, to a large extent, the revival of the Irish language has been predicated on such national pride." Furthermore, the construction of Irish identity was based on the opposite of the notion of Englishness and anything attached to it. Watson [69] exemplifies this point by stating the following:

The image of Englishness against, which Irishness was contructed [sic], was of Protestant people living in cities, playing sports like rugby, football (soccer) and cricket and speaking English. The Irish idyll was a rural, Catholic society playing sports like (Gaelic) football and hurling and speaking Irish.

The desire to create an identity that contrasts with anything British, particularly anything English, derives from the historical, political, and religious tensions between Ireland and England (the UK) in their past relationship. Bernie emphasised this idea in one of his comments:

I'm Irish, I'm from Dublin, and Dublin is not in the UK. So, we have the Irish language, but we had been ... We were colonised by the English 800 years ago, so they kind of forced English upon us. They did this to us.

Here, Bernie is clearly attempting to emphasise his Irish identity, which he believes contrasts to any English identity. Although he does not deny the fact that English is his first and only language, he does refuse to be seen as "English" because of his monolingualism. Whilst Bernie may be viewed by others as a "native speaker" of English, he considers himself to be a "speaker of English" and rejects the idea that the word "native" equates to being an "English" speaker of English because the term "native" diminishes his status as an "Irish" speaker of English. Nevertheless, he was recruited by the Saudi state university based on the assumption that he is, like the rest of the studied group, a "native speaker" of English because English is not only one of the Republic of Ireland's official languages and the predominant language used there but also the only language he speaks. However, in the same way that the study participants noted the limitations of defining a "native speaker" in terms of one's place of birth, they also did not view the official status of English in South Africa and Ireland in the same way simplistic in which it has been used by those such as recruiters and students when defining who they see as a "native speaker." They believed that recruiters impose the term "native speakers" on individuals who may have deep issues with that label, issues that are rooted in complex identity, political, or historical concerns.

Therefore, it should not be assumed that the official use of English in a given country is a straightforward and uncontroversial yardstick to employ when defining a "native speaker" because the official use of English in some countries is the result of the colonisation era, and therefore, on that basis, some of those who come from once-colonised countries may not welcome the label "native speaker," especially if their histories and identities have not been addressed.

6.3. Feeling Guilty. According to Ruecker [27], many "native speaker" teachers who teach abroad enjoy the advantages of their "native speaker" status and view their careers abroad as thrilling "adventures," whilst those who are doomed to be viewed as "nonnative speaker" teachers struggle to find a job and, when recruited, barely make enough money to support their families. Such a view seems to demonise "native speaker" teachers and depict them as individuals who are satisfied with the status quo at the expense of the "nonnative speaker" teachers. However, in the main, the "native speaker" teachers who participated in this study did not seem to be pleased with that situation. They expressed their disapproval of English language teachers being chosen on the assumption that they are "native speakers." Matt points out the following:

It's hard because, technically, there already is sort of a blueprint in place to differentiate them from us. There is this other ring that happens on a bureaucratic level. In the trenches, as it were, in the day-to-day grind of sharing the workload and being in the office together and conversing, it certainly is very, very unfair. There's guilt that happens, there's outrage, I guess, that happens one feels but, really, what can you do about it? Well, I guess you could try and confront management with it. I guess you could try as far as you could, but the bureaucracies are already there, the red tapes are already there.

Adam also shared his feeling of guilt about the pay gap between him and "nonnative speaker" teachers he worked within Vietnam and Thailand:

I've come from Thailand, moved to Vietnam, earned considerably more. As I said, you're co-teaching, so half of the staff room, you can see your colleagues are earning ... really an eighth, a tenth, of what I'm earning, to do essentially the same job. We're working from the same materials. It's just the syllabus has been split. There is a definite guilt ... there was a tension in the room. I mean, the staff room is largely divided on cultural grounds anyway, but even when it came to teaching methodologies, there was surprisingly little interaction across the room in terms of seeking advice or tips. Yeah, there was a palpable divide.

The pay gap that Adam had experienced between himself and his "nonnative speaker" counterparts is prevalent in many countries around the world. The fact that their "nonnative speaker" colleagues were doing the same job and using the same teaching materials but being paid less left both Matt and Adam feeling guilty for receiving a higher salary than they did. This feeling of guilt may be related to what it is called white guilt in which white people are aware that they have unjustified advantages over other racial groups simply because of the colour of their skin [70]. Such feelings can come in the form of negative feelings such 
as anxiety, anger, disgust, and disappointment. Grzanka et al. [71] explain this type of guilt saying that it could be defined as "negative, unpleasant feelings about one's actions, behavior, or attitudes" (p. 50). They go on to explain that "Individuals do not have to personally engage in negative behavior in order to feel guilty; mere association with a group viewed negatively in the past or present can trigger feelings of guilt" (p. 50). Such feelings were apparent in Matt's choice of words such as "outrage" and "very, very unfair." Furthermore, the "tension in the room" and the "palpable divide" that Adam referred to in his remarks are typical outcomes of discriminatory practices which hinder any attempts to bridge the divide across racial and ethnic groups [72]. As a result of their recognition of the injustice that their nonnative colleagues did the same work for less pay and their deep disapproval of the discriminatory practices which recruiters imposed on their "nonnative" coworkers, the participants experienced negative feelings and frustration with the system. Even when Matt attempted to confront management over such discriminatory practices, he was faced with a bureaucratic system that was difficult to penetrate. Therefore, "native speaker" teachers may not happily exploit their privileged status. Instead, like their "nonnative speaker" counterparts, they are simply looking for job opportunities that happen to favour them.

\section{Conclusion}

The findings in this article have shown that "native speaker" teachers view definitions of who is a "native speaker" that are based on a teacher's place of birth or the fact that English is an official language in the country they come from as overly simplistic. Although they did consider the place of birth and the official status of English in a given country as two defining criteria, their more nuanced interpretations of these characteristics indicated that they did not view these defining characteristics in the same way they are used by those such as recruiters, students, and some academic scholars to define a "native speaker." Therefore, three conclusions can be drawn from the findings.

First, although the place of birth was an indication of someone's "native speaker" status, it was not a definitive criterion. Some participants who were born in an ostensibly English-speaking country such as South Africa did not view themselves as "native speakers" but rather as competent English language speakers, even though they were recruited on the assumption that they were "native speakers." They viewed themselves as bilinguals. Those who viewed the place of birth as a defining factor of a "native speaker" were monolinguals, reflecting Jenkins' [46] argument that monolingualism has become the norm that defines a "native speaker." Nonetheless, even the monolingual participants argued that a very high level of proficiency in a language could be acquired at a later stage in life. Therefore, the participants' views on an individual's place of birth did not reflect the rather blunt oversimplification that one's place of birth automatically indicated that a person was a "native speaker" of the language of the person's place of birth, an assumption that has been made by some recruiters and students.
Second, the official status of English in a given country is widely used by recruiters as a criterion for defining a "native speaker." However, once again, the participants in this study indicated more complex perceptions of the role of English in their countries. English is one of 11 official languages in South Africa, and therefore, defining and describing all South Africans as "native speakers" of English undermines the political, sociological, and historical backgrounds of those language groups. Similarly, Ireland, which is a Western country-with all the reservations that come with the term-has two official languages: English and Irish. Nevertheless, despite the decline of Irish and the significant attempts to revive it, it is seen as an official language of the Irish people in terms of its strong link to their identity. Therefore, viewing all Irish people as "native speakers" of English with little recognition of Ireland's heritage and history and many conflicts between English (British) and Irish over colonisation, religion and language undermine the complex subtleties that underpin their identities as "native" speakers of English. Thus, although the official status of English in a given country such as South Africa or the Republic of Ireland may be a broadly useful indication of an individual's "native speaker" status, the participants showed concerns that being defined as "native speakers of English" could overlook their own linguistic heritages and non"English" cultures.

Finally, although the participants were favoured over their "nonnative speaker" counterparts by their recruiters, they did not approve of such discriminatory practices, even though they were benefitting from such privilege. In some cases, they attempted to confront their recruiters over these discriminatory practices. However, the task was challenging because of the bureaucratic management system they encountered. When they turned to their "nonnative speaker" colleagues to bridge the gap between both groups and ease any tension between them, these discriminatory practices were the elephant in the room that hindered such initiatives. Therefore, it should not be assumed that "native speaker" teachers actively seek or are comfortable with the advantages conferred on them. As this study reveals, they believe that the recruiters should be held responsible for the divide they have created between "native" and "nonnative" English language teachers and the deteriorating employment situation of "nonnative speaker" teachers.

Thus, a distinction should be drawn between nativespeakerism [12] and the "native speaker" teacher. The discriminatory practices against "nonnative speaker" teachers that result from the native-speakerism ideology are not necessarily the responsibility of those who are privileged as "native speakers" nor are those who are doomed to be disadvantaged for being defined as "nonnative speakers" responsible for their lower status. It is now time for the whole of the TESOL education system to confront the inequitable status quo that still pertains in countries such as Saudi Arabia and elsewhere in certain parts of the world as a result of the unchallenged and limited criteria that some recruiters use to define a "native speaker." In other words, one should blame the message sender not the messenger. 


\section{Limitations of the Study and Suggestions for Further Research}

A major limitation of this study is the small number of participants. Although more than 30 participants were invited to take part in this research, only 10 of them participated. Therefore, the data from this study cannot be generalised to a larger population. Nevertheless, the study has provided in-depth insights into the topic from the "native speaker" teachers' perspectives, a perspective which has not been sufficiently discussed in research. Another limitation of the study is the context of the research. At the time when the study was conducted, all the participants worked at the same place: a Saudi state university, which may have limited the diversity of their lived experiences.

That said, they were able to draw on their experiences of teaching in many other countries over a number of years. Further research should consider a larger sample of participants in order to provide richer data which could lead to more generalisable conclusions. Furthermore, researchers should also consider diversifying the contexts of future studies and choose participants from different workplaces and countries in order to provide more comprehensive conclusions.

\section{Implications}

This study provides two main implications for those such as English language schools, recruiters, and students who are involved in the TESOL field. First, there is no linguistic evidence which suggests that "native speaker" teachers are more capable teachers than their "nonnative speaker" counterparts. The concept of the "native speaker" is politically and socially constructed rather than scientifically proven. Like their "nonnative speaker" counterparts, the teaching qualities of "native speaker" teachers come from their professional training and qualifications rather than acquired rights from birth, the official language of their home country, or the accent with which they speak. Therefore, when recruiting English language teachers, the search focus should be on the qualifications and professional qualities of the applicants regardless of their place of birth or nationality. Second, although "native speaker" teachers receive unjustified privileges because of their "native speaker" status, whilst their "nonnative speaker" colleagues do not enjoy similar benefits, it should not be assumed that "native speaker" teachers approve of such practices. Such privileges create a divisive atmosphere which can lead "nonnative speaker" teachers to consider their "native speaker" colleagues as opponents or rivals. It is recommended that both groups should work together to challenge the ideology of native-speakerism and to confront discriminatory practices when they occur.

\section{Data Availability}

The data that support the findings of this study are available upon request to the author. The data are not publicly available due to information contained that could compromise the privacy of research participants.

\section{Conflicts of Interest}

The author declares that there are no conflicts of interest.

\section{Acknowledgments}

The author would like to thank and express appreciation to the Deanship of Scientific Research at King Faisal University, Saudi Arabia, for the financial support under Nasher Track (Grant no. 216088).

\section{References}

[1] S. Yun Tsou and Y. Ling Chen, "EFL college students' perceptions toward native and non-native English speaking teachers," American Journal of Educational Research, vol. 5, no. 12, pp. 1182-1190, 2017.

[2] A. Mahboob, "Native or non-native: what do the students think," Learning and Teaching from Experience, pp. 121-147, University of Michigan Press, Ann Arbor, MI, USA, 2004.

[3] M. H. Said and D. Al-Jamal, "Students' perceptions of their native and non-native teachers' effect on their oral fluency: EFL context as an example," Indonesian Journal of Learning and Instruction, vol. 1, no. 1, pp. 1-12, 2018.

[4] M. Gazan and B. Yildirim, "Students' perceptions towards their native English speaking and non-native English speaking teachers," Master's dissertation, Middle East Technical University, Ankara, Turkey, 2016.

[5] M. Kiczkowiak, 'Students', teachers' and recruiters' perception of teaching effectiveness and the importance of nativeness in ELT," Journal of Second Language Teaching \& Research, vol. 7, no. 1, pp. 1-25, 2019.

[6] M. Alqahtani, "The language teacher and native-speakerism in Saudi English Medium Schools: pride or prejudice?" TESOL International Journal, vol. 16, no. 3, pp. 118-143, 2021.

[7] O. Alenazi, "EFL teachers employability in Saudi Arabia: native and non-native speakers," GSTF Journal of Law and Social Sciences, vol. 2, no. 1, pp. 310-315, 2012.

[8] A. Mahboob and R. Golden, "Looking for native speakers of English: discrimination in English language teaching job advertisements," Voices in Asia Journal, vol. 1, no. 1, pp. 72-81, 2013.

[9] A. F. Selvi, "All teachers are equal, but some teachers are more equal than others: trend analysis of job advertisements in English language teaching," WATESOL NNEST Caucus Annual Review, vol. 1, no. 1, pp. 155-181, 2010.

[10] D. Correa, "An equal employment opportunity composite indicator: constructing a measure of progress towards more equitable NNEST employment practices and policies," Master's dissertation, University of Nottingham, Nottingham, UK, 2018.

[11] D. Crystal, Language and the Internet, Cambridge University Press, Cambridge, UK, 2006.

[12] A. Holliday, The Struggle to Teach English as an International Language, Oxford University Press, Oxford, UK, 2005.

[13] G. Braine, Nonnative Speaker English Teachers: Research, Pedagogy, and Professional Growth, Routledge, Oxfordshire, UK, 2010.

[14] S. Canagarajah, "Multilingual writers and the academic community: towards a critical relationship," Journal of English for Academic Purposes, vol. 1, no. 1, pp. 29-44, 2002.

[15] D. Graddol, English Next: Why Global English May Mean the End of "English as a Foreign Language", British Council, London, UK, 2006. 
[16] A. Holliday, "Native-speakerism," ELT Journal, vol. 60, no. 4, pp. 385-387, 2006.

[17] A. Holliday, "Standards of English and politics of inclusion," Language Teaching, vol. 41, no. 1, pp. 119-130, 2008.

[18] A. Holliday, "Native-speakerism," in The TESOL Encyclopedia of English Language Teaching, J. I. Liontas, Ed., pp. 1-7, John Wiley \& Sons, Hoboken, NJ, USA, 2017.

[19] B. Kumaravadivelu, Language Teacher Education for a Global Society: A Modular Model for Knowing, Analyzing, Recognizing, Doing, and Seeing, Routledge, Oxfordshire, UK, 2012.

[20] B. Kumaravadivelu, "The decolonial option in English teaching: can the subaltern act?” Tesol Quarterly, vol. 50, no. 1, pp. 66-85, 2016.

[21] A. Mahboob, The NNEST Lens: Non Native English Speakers in TESOL, Cambridge Scholars Publishing, Newcastle upon Tyne, UK, 2010.

[22] L. Moussu and E. Llurda, "Non-native English-speaking English language teachers: history and research," Language Teaching, vol. 41, no. 3, pp. 315-348, 2008.

[23] N. Rudolph, A. F. Selvi, and B. Yazan, "Conceptualizing and confronting inequity: approaches within and new directions for the "NNEST movement"," Critical Inquiry in Language Studies, vol. 12, no. 1, pp. 27-50, 2015.

[24] A. Holliday, "Native-speakerism: taking the concept forward and achieving cultural belief," in Countering Native-Speakerism, A. Swan, P. Aboshiha, and A. Holliday, Eds., Springer, Berlin, Germany, pp. 11-25, 2015.

[25] D. Benattabou, "Helping EFL students avoid socio-pragmatic failure: focus on nonverbal intercultural competence," TESOL and Technology Studies, vol. 1, no. 1, pp. 23-41, 2020.

[26] E. Clark and A. Paran, "The employability of non-nativespeaker teachers of EFL: a UK survey," System, vol. 35, no. 4, pp. 407-430, 2007.

[27] T. Ruecker, "Challenging the native and nonnative English speaker hierarchy in ELT: new directions from race theory," Critical Inquiry in Language Studies, vol. 8, no. 4, pp. 400-422, 2011.

[28] S. Griffith, Teaching English in Asia: Where and How to Find ESL Jobs, http://www.transitionsabroad.com/listings/work/ esl/articles/workinasia.shtml, 2015.

[29] M. Jung, The Hagwon Color Line: Korean Language Institutes and Their Inexcusably Racist Employment Habits, The Korea Times, Seoul, South Korea, 2014.

[30] J. Saengngoen, Native-Speakerism: Non-White and Non-Native English Teachers in the ESL/EFL Field with a Focus on Thailand and Southeast Asia, Department of Language, Literacy, and Sociocultural Studies, University of New Mexico, Albuquerque, New Mexico, 2014.

[31] S. Ali, "3. Teaching English as an international language (EIL) in the Gulf Corporation Council (GCC) countries: the Brown Man's burden," in English as an International Language: Perspectives and Pedagogical Issues, F. Sharifian, Ed., Multilingual Matters, Bristol, UK, pp. 34-57, 2009.

[32] S. Tatar and S. Yildiz, "Empowering nonnative-English speaking teachers in the classroom," in The NNEST Lens: Non Native English Speakers in TESOL, A. Mahboob, Ed., pp. 114-128, Cambridge Scholars Publishing, Newcastle upon Tyne, UK, 2010.

[33] E. A. Anchimbe, The Native-Speaker Fever in English Language Teaching (ELT): Pitting Pedagogical Competence against Historical Origin, https://www.linguistik-online.net/26_06/ anchimbe_a.html, 2006.

[34] A. Davies, The Native Speaker: Myth and Reality, Multilingual Matters, Bristol, UK, 2003.
[35] K. Rajagopalan, "Non-native speaker teachers of English and their anxieties: ingredients for an experiment in action research," in Non-Native Language Teachers, E. Llurda, Ed., Springer, Berlin, Germany, pp. 283-303, 2005.

[36] R. Kubota and A. M. Lin, Eds., Race, Culture, and Identities in Second Language Education: Exploring Critically Engaged Practice, Routledge, Oxfordshire, UK, 2009.

[37] S. Ashraf, Identity Matters: Stories of Non-Native EnglishSpeaking Teachers' Experiences under the Shadow of Native Speakerism, https://ore.exeter.ac.uk/repository/handle/10871/ 24106, University of Exeter, Exeter, UK, 2016, https://ore. exeter.ac.uk/repository/handle/10871/24106.

[38] D. Lasagabaster and J. M. Sierra, "What do students think about the pros and cons of having a native speaker teacher?," in Non-Native Language Teachers, E. Llurda, Ed., Springer, Berlin, Germany, pp. 217-241, 2005.

[39] M. Romney, "The colour of English," in The NNEST Lens: Non Native English Speakers in TESOL, A. Mahboob, Ed., pp. 18-34, Cambridge Scholars Publishing, Newcastle upon Tyne, UK, 2010.

[40] T. M. Paikeday, "May I kill the native speaker?" Tesol Quarterly, vol. 19, no. 2, pp. 390-395, 1985.

[41] R. Phillipson, Linguistic Imperialism, Oxford University Press, Oxford, UK, 1992.

[42] G. A. Aneja, "(Non) native speakered: rethinking (Non) nativeness and teacher identity in TESOL teacher education," Tesol Quarterly, vol. 50, no. 3, pp. 572-596, 2016.

[43] R. J. Lowe and R. Pinner, "Finding the connections between native-speakerism and authenticity," Applied Linguistics Review, vol. 7, no. 1, pp. 27-52, 2016.

[44] M. B. H. Rampton, "Displacing the "native speaker": expertise, affiliation, and inheritance," ELT Journal, vol. 44, no. 2, pp. 97-101, 1990.

[45] A. Davies, The Native Speaker in Applied Linguistics, Edinburgh University Press, Edinburgh, UK, 1991.

[46] J. Jenkins, The Phonology of English as an International Language, Oxford University Press, Oxford, UK, 2000.

[47] C. Kramsch, Rhetorical Models of Understanding. Functional Approaches to Written Text: Classroom Applications, pp. 5063, ERIC, San Antonio, TX, USA, 1997.

[48] M. Byram, Teaching and Assessing Intercultural Communicative Competence, Multilingual Matters, Bristol, UK, 2021.

[49] M. A. Alseweed, "University students' perceptions of the influence of native and non-native teachers," English Language Teaching, vol. 5, no. 12, pp. 42-53, 2012.

[50] A. Qadeer, "Saudi EFL learners' perceptions about the teaching of English by native and nonnative English teacher," Arab World English Journal, 2019.

[51] C. Kramsch, "The privilege of the nonnative speaker," PMLA, vol. 112, no. 3, pp. 359-369, 2003.

[52] P. Pema Dendup, "The beliefs and practices of Bhutanese English teachers in teaching grammar in English as a second language (ESL) classroom in Bhutan," International Journal of Linguistics and Translation Studies, vol. 1, no. 2, pp. 84-99, 2020.

[53] R. Fithriani, "Discrimination behind nest and nnest dichotomy in ELT pofesionalism," KnE Social Sciences, vol. 3, no. 4, pp. 741-755, 2018.

[54] M. Byram, Teaching and Assessing Intercultural Communicative Competence, Multilingual Matters, Bristol, UK, 1997.

[55] M. Lichtman, Understanding and Evaluating Qualitative Educational Research, Sage Publications, Thousand Oaks, CA, USA, 2010. 
[56] M. van Manen, Researching Lived Experience: Human Science for an Action Sensitive Pedagogy, The Althouse Press, London, UK, 2nd edition, 1997.

[57] R. Burgess, The Field: An Introduction to Field ResearchRoutledge, Oxfordshire, UK, 1984.

[58] B. Kelly, "Focus group interviews," in Research in the College Context, F. K. Stage and K. Manning, Eds., pp. 49-62, Brunner-Routledge, Oxfordshire, UK, 2003.

[59] L. M. Gray, G. Wong-Wylie, G. R. Rempel, and K. Cook, "Expanding qualitative research interviewing strategies: zoom video communications," Qualitative Report, vol. 25, no. 5, pp. 1292-1301, 2020.

[60] J. L. Oliffe, M. T. Kelly, G. Gonzalez Montaner, and W. F. Yu Ko, "Zoom interviews: benefits and concessions," International Journal of Qualitative Methods, vol. 20, 2021.

[61] J. W. Creswell, Qualitative Inquiry and Research Design: Choosing among Five Approaches, Sage Publications, Thousand Oaks, CA, USA, 2007.

[62] V. Braun and V. Clarke, "Using thematic analysis in psychology," Qualitative Research in Psychology, vol. 3, no. 2, pp. 77-101, 2006.

[63] B. B. Kachru, "World Englishes and Applied Linguistics," World Englishes, vol. 9, no. 1, pp. 3-20, 1990.

[64] P. Medgyes, "Native or non-native: who's worth more?" ELT Journal, vol. 46, no. 4, pp. 340-349, 1992.

[65] T. Scovel, "Foreign accents, language acquisition, and cerebral dominance," Language Learning, vol. 19, no. 3-4, pp. 245-253, 1969.

[66] T. Scovel, “"The younger, the better" myth and bilingual education," Language Ideologies: Critical Perspectives on the Official English Movement, vol. 1, pp. 114-136, 2000.

[67] R. Hindley, The Death of the Irish Language, Routledge, Oxfordshire, UK, 2012.

[68] T. J. Ó Ceallaigh and Á. Ni Dhonnabhain, "Reawakening the Irish language through the Irish education system: challenges and priorities," International Electronic Journal of Environmental Education, vol. 8, no. 2, pp. 179-198, 2015.

[69] I. Watson, "Irish language and identity," in A New View of the Irish Language, C. Nic Pháidín and S. Ó Cearnaigh, Eds., Palgrave Macmillan, London, UK, 2008.

[70] J. K. Swim and D. L. Miller, "White guilt: Its antecedents and consequences for attitudes toward affirmative action," Personality and Social Psychology Bulletin, vol. 24, pp. 500-514, 1999.

[71] P. R. Grzanka, K. A. Frantell, and R. E. Fassinger, "The White Racial Affect Scale (WRAS): a measure of white guilt, shame, and negation," The Counseling Psychologist, vol. 48, no. 1, pp. $47-77,2020$.

[72] J. R. Miles, J. T. Muller, J. E. Arnett III, J. R. Bourn, M. C. Johnson, and D. Recabarren, "Group member affect and session evaluations in intergroup dialogue," Group Dynamics: Theory, Research, and Practice, vol. 19, no. 4, pp. 225-242, 2015. 